\title{
Proposta de método de dosagem para argamassas de revestimento com areia artificial de britagem
}

\author{
Proposal for a mix design method for coating mortar with \\ artificial crushing sand
}

\author{
White J osé dos Santos \\ Rita de Cassia Silva Sant'Ana Alvarenga \\ Leonardo Gonçalves Pedroti \\ Reginado Carneiro da Silva \\ Antonio Serpa Freire \\ Bruna Antunes de Moraes \\ Clara Cordeiro Carvalho
}

White J osé dos Santos Universidade Federal de Minas Gerais Belo Horizonte - MG - Brasil

Rita de Cassia Silva Sant'Ana Alvarenga Universidade Federal de Viçosa Viçosa - MG - Brasil

Leonardo Gonçalves Pedroti Universidade Federal de Viçosa Viçosa - MG - Brasil

Reginaldo Carneiro da Silva Universidade Federal de Viçosa Viçosa - MG - Brasil

Antonio Serpa Freire Universidade Federal de Minas Gerais Belo Horizonte - MG - Brasil

Bruna Antunes de Moraes Universidade Federal de Minas Gerais Belo Horizonte - MG - Brasil

Clara Cordeiro Carvalho Universidade Federal de Minas Gerais Belo Horizonte - MG - Brasil

Recebido em 12/03/16 Aceito em 17/02/17

\section{Resumo}

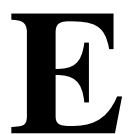

ste trabalho teve por objetivo propor e analisar um método de dosagem experimental para argamassas de revestimento utilizando como agregado miúdo a areia artificial de britagem. Buscou-se identificar e padronizar procedimentos de dosagem de modo a atender a uma condição de obra para um revestimento de argamassa externo, segundo as especificações da ABNT NBR 13281:2005 (ABNT, 2005a). O método de dosagem proposto foi verificado com ensaios de teor de ar incorporado, resistências à compressão e tração na flexão e por resistência de aderência à tração, módulo de elasticidade, absorção de água, porosidade, fissurabilidade, imagens de microscópio digital e testes estatísticos. Empregou-se cimento Portland do tipo II com escória de alto forno, cal hidratada do tipo I e areia artificial de britagem de gnaisse. Concluiu-se que o método proposto é eficiente e permite obter argamassas de revestimento de boa qualidade utilizando areia artificial de britagem, de acordo com as condições preestabelecidas. Há facilidade e flexibilidade na forma de obtenção dos teores de cada componente e do traço adequado, sendo uma boa alternativa para a realização desse tipo de dosagem.

Palavras-chave: Método de dosagem. Areia artificial de britagem. Argamassa de revestimento. Condições construtivas.

\section{Abstract}

The aim of this study was to propose and analyse an experimental mix design method for coating mortars using artificial crushing sand as fine aggregate. We sought to identify and standardize the mix design procedures so as to fulfil the working conditions for an external mortar coating under the specifications of ABNT NBR 13281:2005 (ABNT, 2005a). The proposed mix design method was assessed using the following tests: entrained air content, compressive strength, flexural strength tests and adherence, modulus of elasticity, water absorption, porosity, cracking, stereoscopic magnifier images and statistical analysis. We used Portland cement type II with blast furnace slag, hydrated lime type I, and artificial crushing sand gneiss. The conclusion of the study is that the proposed method is efficient and produces good quality coating mortars using artificial crushing sand, according to pre-established conditions. It is an easy and flexible way to obtain the appropriate levels of each component and the appropriate trait, representing a good alternative for the performance of this type of dosage.

Keywords: Mix design method. Artificial crushing sand. Coating mortar. Constructive conditions. 


\section{Introdução}

Nos últimos anos, muitas empresas estão substituindo a dosagem e a mistura das argamassas em obra pelas pré-fabricadas (só adição de água), devido à dificuldade de estoque e caracterização de materiais e sua dosagem de forma eficiente no canteiro de obras (BARBOSA; SANTOS, 2013). Os métodos de dosagem atualmente disponíveis para argamassas de revestimento e assentamento apresentam abordagens limitadas, muitas vezes com aplicabilidade restrita a determinada região ou em função de algum tipo de equipamento e material específicos. Podem-se citar alguns trabalhos, como o de Selmo (1989), que se baseou na definição do teor ótimo de material plastificante (como saibro, filitos, cal ou pó de calcário) e água para consistência desejada, sendo indicadas algumas verificações (existência de fissuras, textura superficial, aderência, resistência superficial, permeabilidade, absorção de água, custo-benefício) conforme condições de obra; Selmo e Helene (1991), que propuseram uma evolução do método anterior com a inserção da cal, com foco em uma condição específica, como a execução de fachadas de edifícios; Lara et al. (1995), que propuseram dosar argamassas a partir de traços básicos (indicados pelos autores), do consumo máximo de finos e da água para a consistência de $260 \pm 10 \mathrm{~mm}$, com processo através de fórmulas e consulta a tabelas; e, por fim, Gomes e Neves (2002), que dosaram plastificantes à base de argilas específicas de uma região (caulim e arenoso da região de Salvador) e estipularam como parâmetros normativos básicos o teor máximo de finos $(<0,075$ $\mathrm{mm}$ ) do agregado de 7\%; a máxima relação entre adição plastificante e total de agregado de 35\%; o consumo de cimento especificado em projeto (tabelado) e características da argamassa no estado fresco (índice de consistência (flow table) de $260 \pm 10 \mathrm{~mm}$, teor de ar incorporado entre 8\% e 17\% e retenção de água superior a 75\%).

Complementarmente, existem dosagens a partir de conceitos de empacotamento de partículas que ajustam as curvas granulométricas do agregado miúdo. Carneiro (1999) constatou que, variando a granulometria do agregado, se podia aumentar o teor de finos inertes em substituição ao cimento sem o aumento do teor de água. Há, ainda, o proporcionamento através de modelamento matemático em softwares estatísticos com Rede Simplex, como os trabalhos de Bahiense et al. (2008) e Destefane e Holanda (2011), nos quais são requeridos pelo menos sete traços de argamassas para se obter a definição do traço ideal.

Percebe-se que, embora haja diversidade de métodos de dosagem, muitos deles não abordam a influência da granulometria, forma dos agregados e propriedades no estado fresco e endurecido necessárias às adequadas condições de uso e aplicação. Fica assim evidenciada a necessidade do desenvolvimento de um método que considere o desempenho da argamassa de revestimento, que está condicionado à aspereza, determinada em função da natureza mineralógica e granulometria do agregado (MENG et al., 2012; SAHMARAN et al., 2009; PENG; HU; DING, 2009); acabamento final (FARIA; SANTOS; AUBERT, 2015); resistência mecânica oriunda dos materiais empregados (PAN; WENG, 2012; PENG; HU; DING, 2009; KADRI; DUVAL, 2002; SAHMARAN et al., 2009), além da dosagem de forma eficiente (SILVA, 2006; ALLWOOD; ASHBY, 2011) e quantidade de água na mistura (HWANG; SOO KO, 2008; KADRY; DUVAL, 2002).

Nesse contexto, este trabalho tem por objetivo a proposição e análise de um método de dosagem experimental para as argamassas de revestimento em função das exigências do local (adotando-se limites da ABNT NBR 13281 (ABNT, 2005a) e das características dos materiais constituintes, sendo o agregado utilizado neste artigo a areia artificial de britagem.

\section{Método de dosagem}

Dosar uma argamassa consiste em estabelecer as proporções dos materiais constituintes da mistura com base em conceitos e propriedades técnicocientíficos fundamentados no tipo de uso da argamassa e nas características dos materiais constituintes. O método de dosagem proposto corresponde a um conjunto de atividades sequenciais (Figura 1) que permite obter um proporcionamento de materiais, desenvolver testes experimentais e definir o traço mais adequado.

\section{Parâmetros dos materiais e do local de aplicação}

Esta proposta tem como princípio para o início do processo de dosagem o conhecimento das seguintes propriedades e condições:

(a) massa específica real e unitária (solta e
compacta);

(b) granulometria do(s) agregado(s) miúdos(s) (incluindo curva granulométrica, dimensão máxima característica, módulo de finura e teor de material pulverulento);

(c) condições ambientais de exposição da argamassa de revestimento; e 
(d) condições normativas e técnicas que devem ser atendidas.

\section{Quantidade de agregado}

A definição do tipo e da quantidade de agregado no traço ocorreu a partir da análise da curva granulométrica, definindo-se a dimensão máxima característica em função do acabamento desejado 2,4 mm para acabamento mais áspero ou 1,2 mm para superfícies mais finas) - e das massas específicas unitárias compactas e reais.

O objetivo da técnica proposta é encontrar traços nos quais se conheça o coeficiente de vazios deixados pelo agregado, de modo que possam ser preenchidos por cimento, cal e água, e até mesmo se definir um percentual de poros (teor de ar incorporado) desejável para a argamassa, conforme a Equação 1.

$100=P_{\text {cimento }}+P_{\text {cal }}+P_{\text {areia }}+P_{\text {água }}+q+p+A$

Eq. 1

Onde:

$P_{\text {cimento }}=$ consumo de cimento no traço, em \%;

$P_{c a l}=$ consumo de cal no traço, em \%;

$P_{\text {areia }}=$ consumo de areia no traço, em \%;

$P_{\text {água }}=$ consumo de água no traço, em \% adotando-se inicialmente 15\%;

$q$ = aditivos, em $\%$ - definido de forma experimental durante o ajuste do traço; $p$ = adições, em \% - definido de forma experimental durante $\mathrm{o}$ ajuste do traço; e

$A=$ teor de ar incorporado no traço, em \% indica-se adotar $0 \%$ para o início dos cálculos.

Propõe-se para a obtenção do consumo percentual (volume aparente) de agregado na mistura a adoção da equação 3 , que é obtida através do conceito do coeficiente de vazios (amplamente utilizado na área de materiais de construção e solos), conforme procedimentos descritos pela Equação 2. A Tabela 1 apresenta alguns traços usuais segundo algumas bibliografias.

$c_{\text {vazios }}=\frac{V_{v}}{V_{t}}=\frac{V_{t}-V_{S}}{V_{t}}=\left(1-\frac{V_{s}}{V_{t}}\right) \cdot 100=(1-$

$\left.\frac{\gamma_{u}}{\gamma_{r}}\right) \cdot 100$

Eq. 2

$P_{\text {areia }}=100-\left[\left(1-\frac{\gamma_{u}}{\gamma_{r}}\right) \cdot 100\right]$

Onde:

$P_{\text {areia }}=$ teor de agregados miúdos no traço, em \%;

$\gamma_{u}=$ massa específica unitária compacta do agregado miúdo, em g/cm³;

$\gamma_{r}=$ massa específica real do agregado miúdo, em $\mathrm{g} / \mathrm{cm}^{3}$;

$c_{\text {vazios }}=$ coeficiente de vazios, em \%;

$V_{s}=$ volume de sólidos, em litros;

$V_{t}=$ volume total, em litros; $\mathrm{e}$

$V_{v}=$ volume de vazios, em litros.

Figura 1 - Fluxograma ilustrativo do método de dosagem

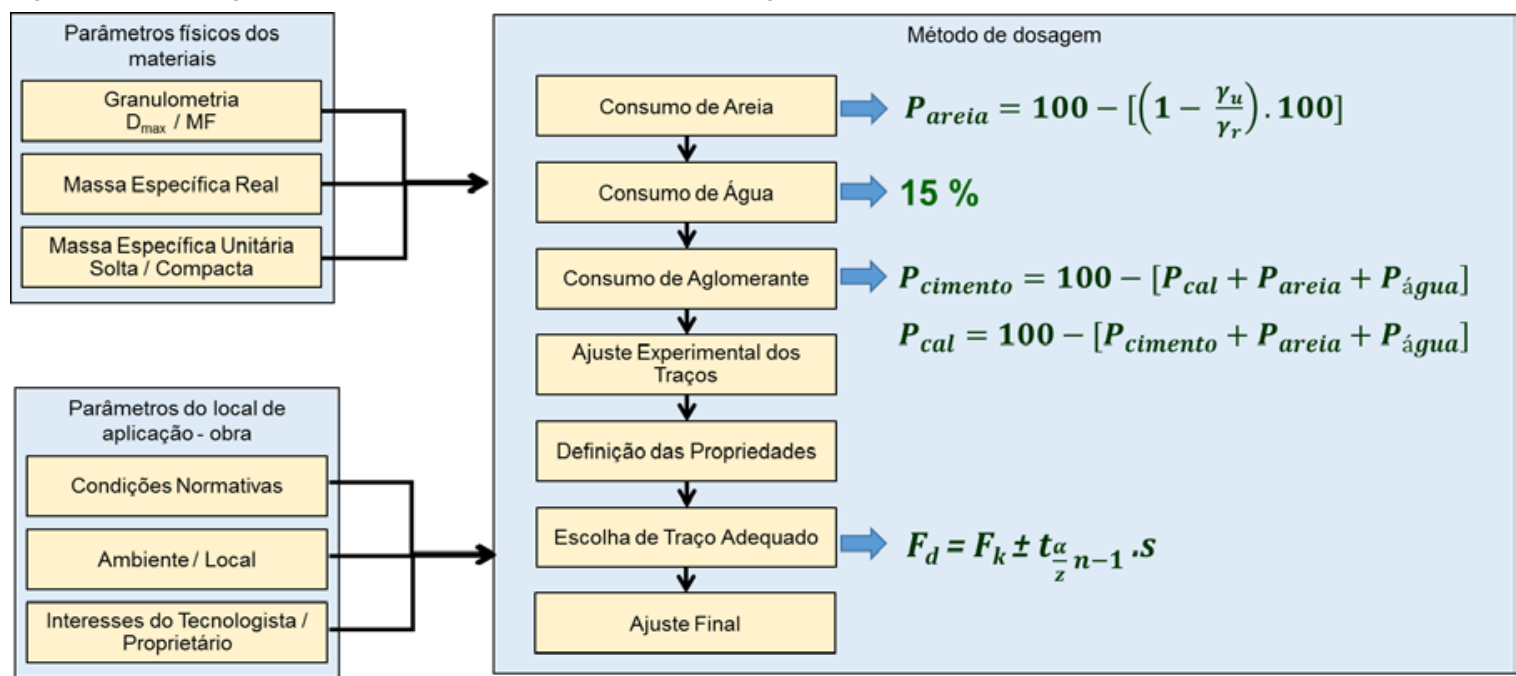


Tabela 1 - Traços básicos em volume aparente e percentual encontrados na bibliografia

\begin{tabular}{c|c|c|c|c|c}
\hline Designação & Cimento & Cal & Areia & Água & Total \\
\hline Traço 1 & 1 & 0,5 & 4,5 & 0,98 & 6,98 \\
Santos (2011) & $14,33 \%$ & $7,16 \%$ & $64,47 \%$ & $14,04 \%$ & $100,00 \%$ \\
\hline Traço 2 & 1 & 1 & 6 & 1,3 & 9,3 \\
Carasek (2010) & $10,75 \%$ & $10,75 \%$ & $64,52 \%$ & $13,98 \%$ & $100,00 \%$ \\
\hline Traço 3 & 1 & 2 & 9 & 2,2 & 14,2 \\
Carasek (2010) & $7,04 \%$ & $14,08 \%$ & $63,38 \%$ & $15,49 \%$ & $100,00 \%$ \\
\hline Traço 4 & 1 & 3 & 12 & 2,7 & 18,7 \\
Carasek (2010) & $5,35 \%$ & $16,04 \%$ & $64,17 \%$ & $14,44 \%$ & $100,00 \%$ \\
\hline Traço 5 & 1 & 1 & 4,5 & 1,1 & 7,6 \\
ASTM C 270:2014 & $13,16 \%$ & $13,16 \%$ & $59,21 \%$ & $14,47 \%$ & $100,00 \%$ \\
\hline (AMERICAN..., 2014) & & & & & \\
\hline
\end{tabular}

Fonte: adaptado de Carasek (2010), Santos (2011) e ASTM C 270:2014 (AMERICAN..., 2014).

Considerando os ajustes aproximados para areia compacta (massa específica compacta aproximadamente $15 \%$ maior que massa específica unitária solta (SANTOS, 2014)), percebe-se que os teores de areia variam entre $67,65 \%$ e $62,24 \%$, o que demonstra que a relação aglomerantes-agregados continua próxima de um terço. Esse método tende a apropriar cientificamente algumas colocações cotidianas da construção civil, tais como a relação agregado-aglomerante manter-se fixa em 3, granulometrias uniformes exigirem mais aglomerantes e serem pouco coesivas (principalmente partículas maiores) e argamassas de revestimento (uso de areia mais fina - passante na peneira $1,2 \mathrm{~mm}$ ) exigirem mais cimento, seja pelo aumento da área específica (maior consumo de água), seja devido ao maior coeficiente de vazios, conforme demonstrado por Haddad (2015). Neste método, ao utilizar essa relação de volume aparente e areia considerando-a compacta, há uma boa aproximação com os traços da Tabela 1 . O uso de areia solta reduz o consumo de areia e maximiza o de cimento, gerando argamassas mais ricas e com maior propensão à fissuração e maior rigidez; logo se justifica a opção pelo uso da massa específica unitária compacta.

Com essa técnica, a especificação da quantidade de componentes deixa de ser arbitrada e passa a ser uma forma de obtenção da quantidade em função do tipo de agregado empregado, bastando somente conhecer sua massa específica unitária seca compacta e a real. Deve-se observar os limites de material coesivo de forma experimental (na fase de ajustes dos traço), de maneira a evitar retração por secagem, gerando fissuras e reduzindo a vida útil do material.

\section{Quantidade de água}

As argamassas de revestimento requerem um percentual de poros que permita sua deformabilidade e solidarização ao substrato, distribuindo esforços (CARASEK, 2010). Cerca de $23 \%$ a $25 \%$ da massa de cimento (MEHTA; MONTEIRO, 2014) será a quantidade de água que reagirá com o cimento, e o restante evaporará deixando poros. Alguns poros permitirão a percolação do $\mathrm{CO}_{2}$ para a carbonatação da cal, sendo preenchidos, e alguns permanecerão abertos. Se o processo de dosagem for adequado, a relação aglomerante-agregado permitirá a geração de poros isolados, originados pelo aditivo incorporador de ar presente na cal, condição ideal para garantir a plasticidade e reologia da argamassa (CARDOSO, 2009; CARASEK, 2010; HADDAD, 2015; SANTOS, 2014).

A definição final da quantidade de água deve ser feita pelo ensaio do índice de consistência, conforme a opção de uso do traço (seca, plástica, fluida). Indica-se o ensaio da mesa de espalhamento (flow table) cujos procedimentos, descritos pela NBR 13276 (ABNT, 2016), são simples, rápidos e de baixo custo. Inicialmente é possível prever a quantidade de água pela Tabela 1 - em torno de 14\%. Diversos trabalhos (FREITAS, 2010; CARASEK, 2010; SANTOS, 2011) observaram que o percentual de água ficava em torno de $15 \pm 5 \%$ do total de materiais. Então, na ausência de referenciais ou necessidades específicas, recomenda-se o valor inicial de 15\%, considerando uma consistência de $260 \pm 10 \mathrm{~mm}$. Lembra-se que a água deve ser adicionada gradualmente, conforme o ajuste do traço à consistência desejada.

\section{Quantidade de aglomerante}

Para revestimento são utilizadas geralmente argamassas mistas (dois aglomerantes - cimento e cal), restando para se calcular o consumo de cimento e cal. Esse detalhamento pode ser feito, novamente, pela análise da literatura (FREITAS, 2010; SANTOS, 2011), que relata um percentual 
mínimo de cada aglomerante de 5\% (para argamassas mistas). Desse modo, têm-se o valor mínimo e o máximo ( $Z$ - Equação 4) de aglomerante em função somente do agregado.

$Z=100-$ Pareia $-5-15$

Pode-se adotar ainda uma expressão que permita obter os consumos de cimento $\left(P_{\text {cimento }}\right)$ em função do consumo atribuído de cal $\left(P_{c a l}\right)$, conforme experiência dos profissionais (Equação 5), ou encontrar o valor da cal em função do cimento, conforme a Equação 6.

$P_{\text {cimento }}=100-\left(P_{\text {cal }}+P_{\text {areia }}+P_{\text {água }}\right)$

$P_{\text {cal }}=100-\left(P_{\text {cimento }}+P_{\text {areia }}+P_{\text {água }}\right)$

Eq. 6

Salienta-se que foi adotada uma aproximação em que percentuais de adições, aditivos e ar incorporado são considerados nulos nessa fase. Eles podem ser inseridos posteriormente, durante o processo de ajuste do traço. Destaca-se que a cal com $100 \% \mathrm{Ca}(\mathrm{OH})_{2}$ geralmente tem a inserção de aditivos incorporadores de ar que auxiliam a argamassa fresca na consistência e coesão inicial (CARASEK, 2010).

\section{Ajuste experimental dos traços básicos}

A partir das etapas anteriores, devem-se extrair pelo menos três traços de argamassa expressos em porcentagem do volume aparente total de materiais (sendo a areia em relação à condição compacta). Esses traços devem ser ajustados de forma experimental, verificando a consistência e, se necessário, acertando a quantidade de água e dos demais materiais na mistura, de acordo com:

(a) exsudação e/ou falta de coesão no material, que podem ser indício de que há pouco aglomerante (energia de compactação muito elevada, agregado com percentual de partículas de diâmetro maior muito grande e/ou granulometria uniforme), sendo necessário o incremento do aglomerante ou adaptações no agregado com a inserção de finos;

(b) coesão excessiva, ou seja, a argamassa fica aderida à colher de pedreiro, mesmo umedecida, sendo indicado acrescentar agregado à mistura e/ou reduzir o teor de finos do agregado ou teor de aglomerantes; e

(c) argamassa muito áspera, indício de que a granulometria da areia possui várias partículas de dimensões maiores. Deve-se fazer o peneiramento do material, retirando a graduação indesejável, e refazer todo o processo de dosagem.

Nesta fase podem-se fazer ajustes como a inserção de adições e aditivos, de modo a tornar a argamassa mais densa, fluida, ou mesmo incorporar ar. Devem ser inseridas no traço, e seus percentuais calculados em relação ao total da mistura.

Destaca-se a necessidade de ajustes e moldagem dos corpos de prova em condições semelhantes às que a argamassa estará submetida no empreendimento. Desse modo, os ajustes serão mais representativos, o que permitirá a observação de possíveis variações, que poderão ser consideradas no desvio padrão para a definição do intervalo de confiança do processo.

\section{Definição das propriedades e idades}

As argamassas de revestimento possuem propriedades que têm maior ou menor relevância em função do local de uso e de especificações normativas. Apresentam-se algumas propriedades a serem consideradas:

(a) no estado fresco: consistência, coesão e retenção de água, que garantirão a trabalhabilidade necessária durante o processo de aplicação e acabamento; e

(b) no estado endurecido: resistência à tração na flexão, potencial de aderência à tração e à compressão, que indicam a capacidade resistente do material, além das propriedades que são indicadores de durabilidade, como porosidade, absorção e fissurabilidade.

É preciso conhecer as condições do local de aplicação e qual a expectativa para a argamassa a ser dosada, e especificar as propriedades que melhor representam a condição ambiental. Indicamse as propriedades resistência à tração na flexão e potencial de aderência à tração, consistência e coesão como mínimas a serem consideradas no planejamento das argamassas de revestimento, visto que são propriedades básicas, e, qualquer que seja a condição, seus resultados são extremamente relevantes. Ressalta-se que consistência e coesão já fazem parte do processo de dosagem, logo devem ser executadas sempre.

Após serem escolhidas as propriedades, deve-se definir as idades a serem analisadas. Muitos estudos (FREITAS, 2010; CARASEK, 2010; SANTOS, 2011) demostram que, para o uso de cimento CPIIE-32, com 14 dias já se obtém cerca de $70 \%$ a $80 \%$ da resistência final, e para CP V, 7 dias. Para casos mais conservadores (a favor da segurança), indicase a idade de referência de 28 dias, que é o convencional para compósitos cimentícios. Ressalta-se que algumas cales apresentam variações em suas propriedades em idades avançadas devido à carbonatação; logo, pode-se avaliar idades maiores, como 80 e 120 dias. 


\section{Definição do traço ideal}

As argamassas de revestimento devem atender a uma condição de dosagem dada pela Equação 7:

$F_{d}=F_{k} \pm t_{\frac{\alpha}{z} n-1} \cdot s$

Onde:

$F_{d}$ corresponde ao limite de dosagem de determinada propriedade da argamassa;

$F_{k}$ corresponde ao limite característico de determinada propriedade da argamassa;

$t_{\frac{\alpha}{z} n-1}$ corresponde a um valor tabelado

(Distribuição $t$ ) para um nível de significância de $5 \%$ (confiabilidade de $95 \%$ ) e grau de liberdade ( $n$ $1)$;

" $s$ " é o desvio padrão da amostra avaliado através de regressão linear de cada propriedade em função dos constituintes dos materiais em porcentagem de volume; e

“ $n$ ” número de amostras.

Para definir o traço ideal, pode-se construir gráficos correlacionando os valores das propriedades (eixo das abscissas) e os percentuais (volumes aparentes) dos materiais utilizados (eixo das ordenadas). Devese utilizar os traços ajustados, sendo indicado que se tenham pelo menos três propriedades e que se busque o traço que atenda aos limites exigidos para todas. A partir dos gráficos, podem-se construir linhas de tendência por uma planilha eletrônica e encontrar as correlações do consumo de cada material para cada propriedade. Encontra-se o traço ideal para cada propriedade atribuindo o valor de $\boldsymbol{F}_{\boldsymbol{d}}$ e encontrando-se o percentual de material para a condição especificada. O traço final é aquele que atende a todas as condições, aquele que estiver mais à direita do gráfico, ou mais próximo do traço mais forte para propriedades com limitações superiores, e traço mais fraco para limitações inferiores.

O processo se encerra com a apresentação do traço nas versões solicitadas (massa, volume, porcentagem, por metro cúbico, por saco de cimento). Indica-se a confecção de uma pequena amostra para verificar a quantidade de água através do ensaio de consistência (na fase de ajustes dos traço) e também a moldagem de corpos de prova com o traço final para verificação das propriedades antes do uso maximizado na obra. Se todos os parâmetros no estado fresco e endurecido estiverem fechados, o processo terminou. Caso contrário, verifica-se algum possível erro durante o processo de dosagem e refaz-se toda a dosagem ou parte dela se necessário.

\section{Material e programa experimental \\ Material}

Foram empregados cimento Portland do tipo II com escória de autoforno, cal hidratada especial aditivada tipo $\mathrm{CH}$ I e agregado miúdo artificial de gnaisse - zona utilizável inferior (Figura 2 e Tabelas 2 e 3). Esse agregado miúdo artificial foi adquirido no comércio de Belo Horizonte, obtido por britador de mandíbula, com caracterização mineralógica por difração de raios $\mathrm{X}$ e eflorescência de raios $\mathrm{X}$, conforme a Figura 2 e a Tabela 2.

\section{Programa experimental}

O programa experimental deste trabalho consistiu na caracterização dos agregados e realização dos ensaios necessários à verificação do método de dosagem de argamassa para revestimento com areia artificial. Os resultados foram avaliados para condições de revestimento externo, com base na NBR 13281 (ABNT, 2005a) e Carasek (2010). Objetivou-se identificar um traço ideal que atendesse às condições expressas na Tabela 4, dentro de um intervalo de confiança unilateral. Foram obtidas, ainda, imagens por microscópio digital para complementação das análises.

O programa experimental foi estruturado segundo o processo de dosagem proposto, para avaliar sua exequibilidade. Os corpos de prova utilizados na primeira fase (traços básicos) correspondem aos limites das normas específicas (Tabela 4); já na segunda fase (verificação do método), para o traço ideal foram confeccionados mais corpos de prova (18 CPs para $f_{t}$ e $A d$; 36 CPs para $f_{c}$; e 10 CPs para $E_{d}, C C, A_{i}$ e $P$ ), de modo a maximizar a amostragem e realizar testes que comprovassem o cumprimento dos parâmetros estipulados.

Tabela 2 - Composição mineralógica da areia artificial de britagem

\begin{tabular}{|c|c|c|}
\hline Minerais & Composição & $\%$ \\
\hline Oligoclásio & Feldspato: $\mathrm{Na}_{0,8} \mathrm{Ca}_{0,2} \mathrm{Al}_{1,2} \mathrm{Si}_{2,8} \mathrm{O}_{8}$; triclínico & Alta \\
\hline Quartzo & $\mathrm{SiO}_{2} ;$ trigonal & Médio \\
\hline Ferro-hornblenda & Anfibólio: $\mathrm{Ca}_{2} \mathrm{Fe}^{2+}{ }_{4} \mathrm{Al}_{0,75} \mathrm{Fe}^{3+}{ }_{0,25}\left(\mathrm{Si}_{7} \mathrm{AlO}_{22}\right)(\mathrm{OH})_{2}$ monoclínico $)$ & \multirow{2}{*}{ Médio baixo } \\
\hline Biotita & Mica: $\mathrm{K}\left(\mathrm{Mg}, \mathrm{Fe}^{2+}\right)_{3} \mathrm{AlSi}_{3} \mathrm{O}_{10}(\mathrm{OH})_{1,75} \mathrm{~F}_{0,25} ;$ monoclínico & \\
\hline Chamosita & Clorita: $\mathrm{Fe}^{2+}{ }_{3} \mathrm{Mg}_{1,5} \mathrm{AlFe}^{3+}{ }_{0,5} \mathrm{Si}_{3} \mathrm{AlO}_{10}(\mathrm{OH})_{8}$; monoclínico & Baixo \\
\hline
\end{tabular}

230 Santos, W. J. dos; Alvarenga, R. de C. S. S.; Pedroti, L. G.; Silva, R. C. da; Freire, A. S.; Moraes, B. A. de; Carvalho, C. C. 
Tabela 3 - Características físicas da areia artificial

\begin{tabular}{c|c}
\hline \multicolumn{2}{c}{ Composição granulométrica (NBR NM 248 (ABNT, 2003)) } \\
\hline Agregado miúdo artificial de britagem & Zona utilizável inferior \\
\hline Dimensão máxima característica & $1,2 \mathrm{~mm}$ \\
Módulo de finura & 1,56 \\
Massa específica real (NBR NM 52 (ABNT, 2009a)) & $2,660 \mathrm{~kg} / \mathrm{dm}^{3}$ \\
Massa específica unitária solta (NBR NM 45 (ABNT, 2006)) & $1,440 \mathrm{~kg} / \mathrm{dm}^{3}$ \\
Massa específica unitária compacta (NBR NM 45 (ABNT, 2006)) & $1,656 \mathrm{~kg} / \mathrm{dm}^{3}$ \\
Teor de argila (NBR 7218 (ABNT, 2010)) & Isento \\
Teor de material pulverulento (NBR NM 46 (ABNT, 2001a)) & $14,78 \%$ \\
Impureza orgânica (NBR NM 49 (ABNT, 2001b)) & $<300 \mathrm{p} . \mathrm{p} . \mathrm{m}$. \\
Absorção de água (NBR NM 30 (ABNT, 2000)) & $5,32 \%$ \\
Forma dos grãos & Anguloso \\
\hline
\end{tabular}

Figura 2 - Resultado da difração de raios $\mathrm{X}$ do agregado miúdo artificial



Tabela 4 - Condições para a dosagem de argamassa de revestimento argamassado

\begin{tabular}{l|l|c|l}
\hline \multicolumn{1}{c|}{ Propriedades } & \multicolumn{1}{c}{ Limite } & CPs & \multicolumn{1}{c}{ NBR } \\
\hline$f_{c}$ - Compressão - P4-P5-P6 & $\geq 4,0 \mathrm{MPa}$ & 6 & 13279 (ABNT, 2005c) \\
\hline$f_{t}$ - Tração na flexão - R4-R5-R6 & $\geq 2,0 \mathrm{MPa}$ & 3 & 13279 (ABNT, 2005c) \\
\hline$A_{d}$ - Tração por aderência - A3 & $\geq 0,30 \mathrm{MPa}$ & 3 & 13528 (ABNT, 2010b) \\
\hline $\begin{array}{l}C C \text { - Coeficiente de capilaridade - C4- } \\
\text { C5-C6 }\end{array}$ & $\leq 7,0 \mathrm{~g} / \mathrm{dm}^{2} \cdot \mathrm{min}^{1 / 2}$ & 4 & 15259 (ABNT, 2005e) \\
\hline $\begin{array}{l}\text { Jfresca - Densidade de massa no estado } \\
\text { fresco - M4-C5-C6 }\end{array}$ & $\geq 1.600 \mathrm{~kg} / 1$ & 4 & 13278 (ABNT, 2005b) \\
\hline $\begin{array}{l}\text { Jseca - Densidade de massa no estado } \\
\text { endurecido - M4-M6 }\end{array}$ & $\geq 1.400 \mathrm{~kg} / 1$ & 4 & 13280 (ABNT, 2005d) \\
\hline $\begin{array}{l}\text { Análise de propensão à fissuração - Baixa } \\
\text { fissurabilidade }\end{array}$ & $E_{d} \leq 7 \mathrm{GPa}$ e $E_{d} / f_{t} \leq 2.500$ & 4 & 15630 (ABNT, 2009a) \\
\hline
\end{tabular}

Fonte: extraído e adaptado de ABNT NBR 13281 (ABNT, 2005a) e Carasek (2010).

Nota: $E_{d}=$ Módulo de elasticidade dinâmico. 
Para facilitar a compreensão, o programa experimental contempla o processo até o ajuste dos traços básicos, sendo o restante descrito nos resultados e análises, uma vez que configura os valores encontrados para os traços básicos e o traço ideal.

Foram utilizados os materiais descritos nas Tabelas 2 e 3 e Figura 2, e a argamassa ideal deverá atender às condições da Tabela 4.

\section{Consumo de areia}

Na Tabela 3 as massas específicas real e unitária compacta são 2,660 kg/l e $1,656 \quad \mathrm{~kg} / \mathrm{l}$ respectivamente. Adotando-se a Equação 3, o consumo de areia obtido é de 62,27\%. Esse percentual permite obter uma argamassa com relação aglomerante-agregado em torno $37 \%$, ou seja, pouco superior a $1 / 3$, que é descrita comumente como uma boa relação. Destaca-se que a areia utilizada é mais fina (módulo de finura igual a 1,56), sendo esperado maior consumo de aglomerante.

\section{Consumo de água}

A argamassa de revestimento estudada necessita de resistência mediana e boa coesão, contudo sem causar retração (excesso de finos, ação do sol e camada muito fina $-10 \mathrm{~mm}$ a $25 \mathrm{~mm}$ ). Optou-se por partir de um consumo de água de $15 \%$ para início do cálculo, considerando que o teor de aglomerantes promoveria coesão aceitável sem retração.

\section{Consumo de aglomerante}

Para definir o traço ideal foi adotada a equação 6, sendo estipulada a quantidade percentual (volume aparente) de cimento para se obter a de cal. Adotouse o percentual intermediário de $10 \%$ de cimento, um traço mais forte ( $+3 \%$ de cimento) e outro mais fraco (-3\% cimento), conforme composições dos traços expressas na Tabela 5.

Foram utilizados os valores de massa específica real e unitária do cimento $(3,10 \mathrm{~kg} / \mathrm{l}$ e $1,70 \mathrm{~kg} / \mathrm{l}$ respectivamente) e da cal $(2,80 \mathrm{~kg} / \mathrm{l}$ e $0,50 \mathrm{~kg} / \mathrm{l}$ respectivamente), fornecidos pelos fabricantes, para transformação dos traços em proporção de massa.

\section{Ajuste do traço}

Os traços foram ajustados (em massa) buscando-se consistência (flow table) de $260 \pm 10 \mathrm{~mm}$, sendo necessário o incremento de água para atender a essa condição. Percebeu-se que os traços apresentaram boa coesão e estavam adequados para o uso como argamassa de revestimento. Com os ajustes, os traços se alteraram um pouco, conforme se observa nos proporcionamentos em porcentagem de volume na Tabela 6.

Tabela 5 - Traços básicos das argamassas de revestimento

\begin{tabular}{l|c|c|c|c|c}
\hline & Unidade & Cimento & Cal & Areia & Água \\
\hline \multirow{3}{*}{$1^{\circ}$ Traço } & $(\%)$ & 7,00 & 15,73 & 62,27 & 15,00 \\
& $(\mathrm{l})$ & 1,000 & 2,247 & 8,896 & 2,143 \\
& $(\mathrm{~kg})$ & 1,000 & 0,661 & 8,667 & 1,261 \\
\hline \multirow{3}{*}{$2^{\circ}$ Traço } & $(\%)$ & 10,00 & 12,73 & 62,27 & 15,00 \\
& $(\mathrm{l})$ & 1,000 & 1,273 & 6,227 & 1,500 \\
& $(\mathrm{~kg})$ & 1,000 & 0,374 & 6,067 & 0,882 \\
\hline \multirow{3}{*}{$3^{\circ}$ Traço } & $(\%)$ & 13,00 & 9,73 & 62,27 & 15,00 \\
& $(\mathrm{l})$ & 1,000 & 0,748 & 4,790 & 1,154 \\
& $(\mathrm{~kg})$ & 1,000 & 0,220 & 4,667 & 0,679 \\
\hline
\end{tabular}

Tabela 6 - Traços ajustados das argamassas de revestimento

\begin{tabular}{c|c|c|c|c|c}
\hline & Unidade & Cimento & Cal & Areia & Água \\
\hline \multirow{3}{*}{$1^{\circ}$ Traço } & $(\mathrm{kg})$ & 1,000 & 0,661 & 8,667 & 1,605 \\
& $(\mathrm{l})$ & 1,000 & 2,247 & 8,896 & 2,729 \\
& $(\%)$ & 6,72 & 15,11 & 59,82 & 18,35 \\
\hline \multirow{3}{*}{$2^{\circ}$ Traço } & $(\mathrm{kg})$ & 1,000 & 0,374 & 6,067 & 1,177 \\
& $(\mathrm{l})$ & 1,000 & 1,273 & 6,227 & 2,001 \\
& $(\%)$ & 9,52 & 12,12 & 59,30 & 19,05 \\
\hline \multirow{3}{*}{$3^{\circ}$ Traço } & $(\mathrm{kg})$ & 1,000 & 0,220 & 4,667 & 0,932 \\
& $(\mathrm{l})$ & 1,000 & 0,748 & 4,790 & 1,584 \\
& $(\%)$ & 12,31 & 9,21 & 58,97 & 19,51 \\
\hline
\end{tabular}

232 Santos, W. J. dos; Alvarenga, R. de C. S. S.; Pedroti, L. G.; Silva, R. C. da; Freire, A. S.; Moraes, B. A. de; Carvalho, C. C. 
Apesar da alteração dos traços, a relação aglomerante-agregado (em volume) se manteve, 0,37, para garantir a coesão adequada à argamassa. Para adquirir a consistência desejada sem segregação, foi necessário aumentar a relação (em massa) água-materiais secos de aproximadamente 0,12 para 0,16 , um aumento em média de $25 \%$, ocasionado pelo teor de finos desse agregado (aumento da área específica) e pela absorção de água maior nos agregados artificiais devido ao processo de britagem (HADDAD, 2015). Não foi necessário o uso de aditivos para atender às características desejadas (resistência mais baixa e maior liberdade do teor de água).

\section{Escolha do traço ideal}

Optou-se por definir o traço para a idade de 28 dias por ser esta uma idade de referência nos compósitos cimentícios (geralmente já possuem propriedades mais estabilizadas), e o objetivo foi escolher um traço que tivesse boas características durante toda a sua vida útil.

\section{Resultados e análises}

Os resultados e análises foram estruturados de modo a avaliar a exequibilidade do método de dosagem proposto e se os constituintes da argamassa influenciam nas propriedades analisadas.

\section{Resultados do processo de dosagem e definição do traço ideal}

A definição do traço ideal corresponde à definição do traço que atenda à condição de dosagem dada pela Equação 7. Para isso se faz necessário, a partir dos resultados obtidos, identificar o desvio padrão encontrado nos experimentos e utilizá-lo no processo de dosagem.
Para se definir o desvio padrão a ser adotado em cada propriedade, devem-se realizar os ensaios dos corpos de prova nas devidas propriedades, de acordo com os procedimentos normativos, e calcular o desvio padrão de cada amostra (verificar os limites de aceitação de cada ensaio). De posse deste, adota-se o maior valor de desvio padrão encontrado entre os três traços para cada propriedade (garante-se, assim, maior segurança no processo de dosagem). Essa medida permite avaliar parâmetros de dosagem de acordo com a variabilidade esperada para a condição de utilização. Logo, devem-se adotar procedimentos semelhantes aos esperados no processo de fabricação, seja em uma indústria ou mesmo em uma obra, para que este desvio seja representativo.

Para chegar ao traço ideal, as argamassas de revestimento devem atender a uma condição de dosagem, sendo adotados neste trabalho os intervalos de limites extremos, ou seja, buscam-se propriedades que devem atingir no mínimo ou no máximo determinado valor da propriedade avaliada. A Tabela 7 reúne os valores característicos (estipulados pela Tabela 4), para $t_{\frac{\alpha}{z} n-1}$ graus de liberdade, maior desvio padrão experimental, e os valores de dosagem de cada propriedade.

O intervalo de confiança ficou definido (Tabela 7) como $F_{d}=F_{k}+t_{\frac{\alpha}{z} n-1} . s$ (valor mínimo) e $F_{d}=F_{k}$ $t_{\frac{\alpha}{z} n-1} . s \quad$ (valor máximo), considerando confiabilidade de 95\%. Admitiu-se que os parâmetros $f_{c}, f_{t}, A_{d}, \gamma_{\text {seca }}, \gamma_{\text {fresca }}$ tivessem os valores de $F_{d}$ (parâmetros de dosagem) maiores que o $F_{k}$ (parâmetros característicos). Já para o coeficiente de capilaridade e a avaliação de tendência à fissurabilidade, optou-se que $F_{d}$ fosse menor que o $F_{k}$ devido ao fato de que, quanto maiores esses parâmetros, menores são as outras propriedades.

Tabela 7 - Valores característicos, $t_{\frac{\alpha}{z} n-1}$ da curva t, de desvio padrão e de dosagem

\begin{tabular}{c|c|c|c|c}
\hline \multirow{2}{*}{ Propriedade } & \multicolumn{4}{|c}{ Areia artificial } \\
\cline { 2 - 5 } & $\mathbf{F}_{\mathbf{k}}$ & $\boldsymbol{t}_{\frac{\boldsymbol{\alpha}}{z} \boldsymbol{n}-\mathbf{1}}$ & Desvio padrão & $\mathbf{F}_{\mathbf{d}}$ \\
\hline$f_{c}(\mathrm{MPa})$ & $>4,000$ & 2,015 & 0,446 & $>4,899$ \\
$f_{t}(\mathrm{MPa})$ & $>2,000$ & 2,920 & 0,094 & $>2,396$ \\
$A_{d}(\mathrm{MPa})$ & $>0,300$ & 2,920 & 0,027 & $>0,377$ \\
$C C\left(\mathrm{~g} / \mathrm{dm}^{2} \cdot \mathrm{min}^{1 / 2}\right)$ & $<7,000$ & 2,353 & 0,250 & $<6,412$ \\
$\gamma$ seca $(\mathrm{kg} / \mathrm{l})$ & $>1,600$ & 2,353 & 0,009 & $>1,602$ \\
$\gamma$ fresca $(\mathrm{kg} / \mathrm{l})$ & $>1,400$ & 2,353 & 0,026 & $>1,460$ \\
$E_{d}(\mathrm{GPa})$ & $<7,000$ & 2,353 & 0,088 & $<6,167$ \\
\hline
\end{tabular}


De posse dos resultados dos experimentos e do valor de dosagem (Tabela 7) de cada propriedade, foram confeccionados os gráficos de proporcionamento de materiais versus cada propriedade para definir as curvas de dosagem e assim encontrar o traço ideal (Figuras 3 a 10).
Aproximaram-se por linha de tendência da planilha eletrônica os três traços, sendo as curvas polinomiais de $2^{\circ}$ grau que melhor representaram os eventos estudados, permitindo, desse modo, estruturar equações de correlação da quantidade de cada material em função de cada propriedade.

Figura 3 - Proporcionamento dos materiais versus resistência à compressão para definição do parâmetro de dosagem $\left(f_{c d}\right)$


Figura 4 - Proporcionamento dos materiais versus resistência à tração na flexão para definição do parâmetro de dosagem $\left(f_{t d}\right)$
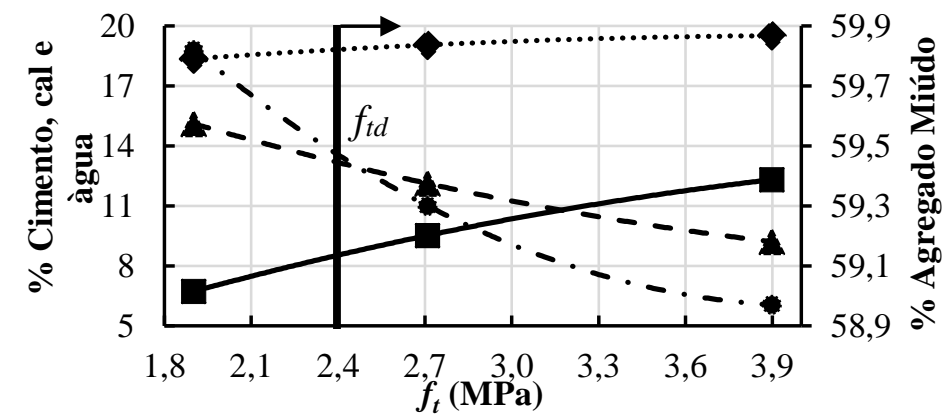

$$
\begin{aligned}
& \text { 을 } \quad P_{\text {cim }}=-0,560 f_{t}^{2}+6,048 f_{t}-2,751 \\
& P_{c a l}=0,628 f_{t}^{2}-6,593 f_{t}+25,374 \\
& P_{\text {areia }}=0,183 f_{t}^{2}-1,488 f_{t}+61,987 \\
& P_{\text {água }}=-0,240 f_{t}^{2}+1,973 f_{t}+15,468 \\
& \begin{array}{ll}
\text { - Areia } & \text { - Cimento } \\
\text { ^Cal } & \bullet \text { Água }
\end{array}
\end{aligned}
$$

Figura 5 - Proporcionamento dos materiais versus resistência potencial de aderência à tração para definição do parâmetro de dosagem $\left(A_{d d}\right)$
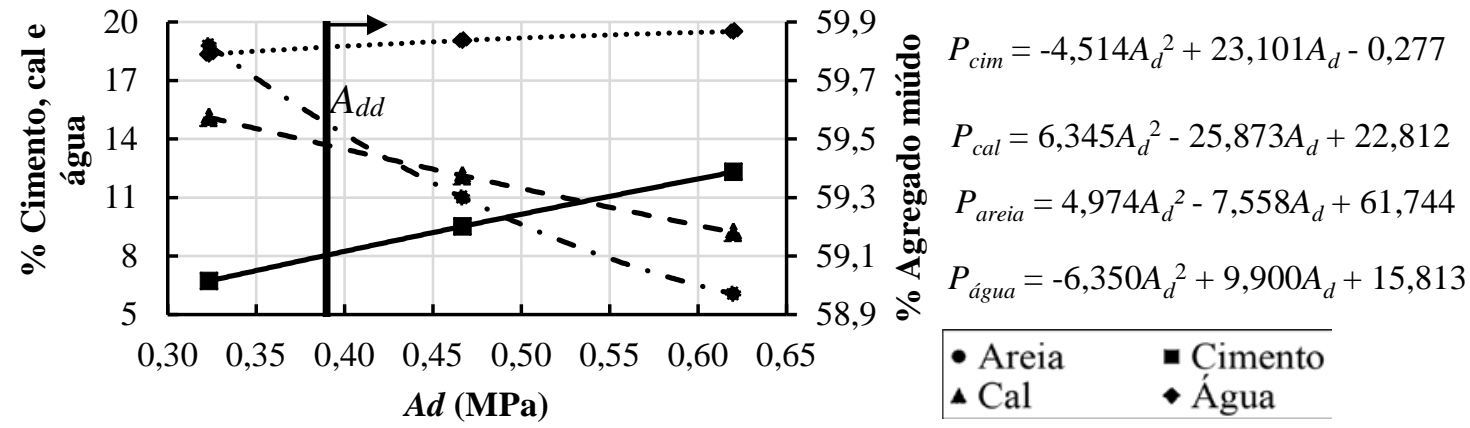

234 Santos, W. J. dos; Alvarenga, R. de C. S. S.; Pedroti, L. G.; Silva, R. C. da; Freire, A. S.; Moraes, B. A. de; Carvalho, C. C. 
Figura 6 - Proporcionamento dos materiais versus coeficiente de capilaridade para definição do parâmetro de dosagem $\left(\mathrm{CC}_{\mathrm{d}}\right)$

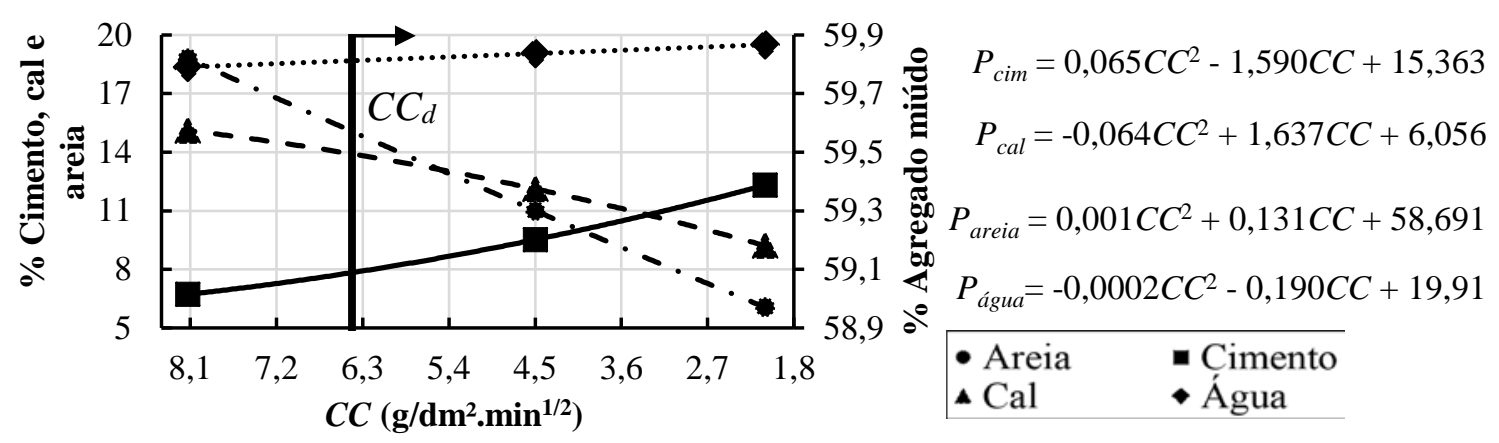

Ressalta-se que outros pesquisadores que desejem replicar esse método de dosagem devem verificar a melhor curva, sendo o $\mathrm{R}^{2}$ uma boa opção para avaliar a aproximação dos resultados. Contudo, é preciso cuidado ao verificar possíveis discrepâncias entre a curva e a tendência dos resultados, ou seja, a curva polinomial do $2^{\circ}$ grau sempre dará $\mathrm{R}^{2}$ igual a 1 quando se avaliarem três pontos, todavia podem conter inflexões que extrapolem a projeção desses resultados. Neste caso, deve-se alterar para outro tipo de curva que tenha um bom $\mathrm{R}^{2}$ (próximo de 1), mas que tenda para projeção média dos resultados encontrados. Neste trabalho seria possível, por exemplo, o uso de aproximação linear com bons resultados de ajuste, não utilizados devido à melhor distribuição em torno dos resultados proveniente das curvas polinomiais. Ressalta-se ainda que as expressões são válidas para os materiais analisados nas condições estipuladas e no intervalo avaliado em cada propriedade; logo, a extrapolação das expressões para valores maiores ou menores pode incorrer em erros.

Durante o processo, constatou-se que a massa específica nos estados fresco e endurecido apresentou valores superiores aos parâmetros estabelecidos em todos os traços analisados, logo foram tratadas como elementos de verificação, sem a necessidade de serem consideradas para a escolha do traço ideal (Figuras 8 e 9). Adotou-se uma avaliação qualitativa de forma a classificar as argamassas quanto à tendência à fissurabilidade, objetivando mantê-las como baixa ou média fissurabilidade, conforme as Figuras 9 e 10.

Diante dos resultados (Figuras 3 a 10), pôde-se encontrar o traço mais adequado para a areia estudada segundo as condições estipuladas. Para a escolha foi avaliado qual propriedade se apresenta mais exigente quanto a seu parâmetro. Por exemplo, que propriedade apresenta a exigência de um traço mais próximo ao mais forte, ou seja, mais à direita do gráfico. Pelos gráficos, percebe-se que a resistência à tração na flexão foi a propriedade limitadora para a areia artificial neste trabalho sendo a linha vertical $\left(F_{d}\right)$ mais próxima do traço 2 .

Foram utilizadas as correlações obtidas nesta propriedade para definir o traço ideal para areia artificial, conforme as Equações 8 a 11.

$\begin{array}{lr}P_{\text {areia }}=0,183 f_{t}^{2}-1,488 f_{t}+61,987 & \text { Eq. } 8 \\ P_{\text {água }}=-0,240 f_{t}^{2}+1,973 f_{t}+15,468 & \text { Eq. } 9 \\ P_{\text {cal }}=0,628 f_{t}^{2}-6,048 f_{t}+25,374 & \text { Eq. } 10 \\ P_{\text {cimento }}=-0,560 f_{t}{ }^{2}+6,593 f_{t}-2,751 & \text { Eq. } 11\end{array}$

Realizou-se o teste Anova para cada correlação realizada na Figura 4 (Equações de 8 a 11) de modo a verificar a significância/dependência entre a propriedade e o consumo de material, sendo identificado que as variações dos componentes foram significativas (grau de significância de 0,05).

A partir das Equações 8 a 11 foi possível encontrar o traço ideal para as condições dos materiais e do ambiente de aplicação, conforme parâmetros especificados na Tabela 4 (Tabela 8).

De forma geral, percebe-se que as propriedades são dependentes da composição do traço, corroborando a literatura (HWANG; SOO KO, 2008; SAHMARAN et al., 2009; SANTOS, 2011). Fica evidente que o método permite avaliar os traços que rodeiam a maioria das propriedades analisadas neste trabalho, garantindo, assim, a definição do traço mais adequado para as condições pesquisadas. 
Figura 7 - Proporcionamento dos materiais versus massa específica no estado endurecido

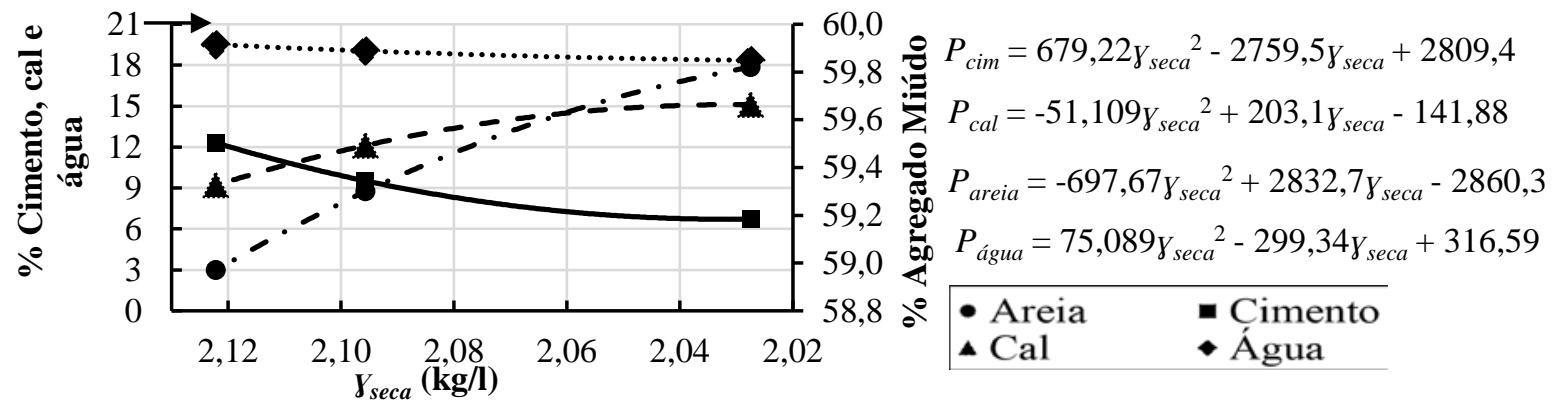

Figura 8 - Proporcionamento dos materiais versus massa específica no estado fresco

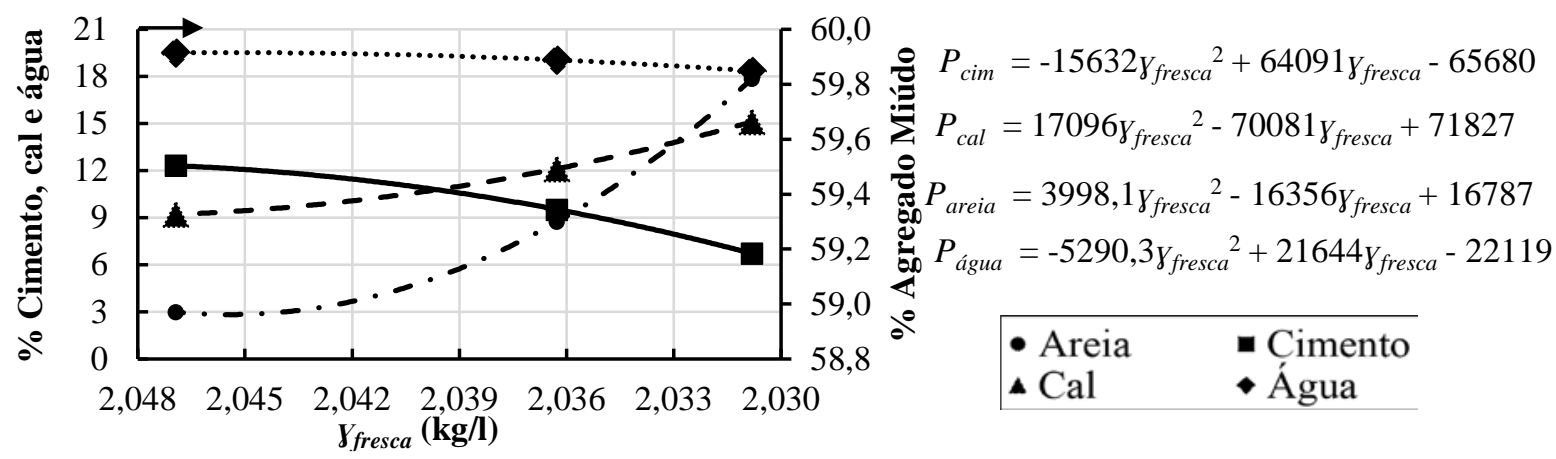

Figura 9 - Proporcionamento dos materiais versus módulo de elasticidade dinâmico para definição do parâmetro de dosagem $\left(E_{d d}\right)$ para baixa fissurabilidade

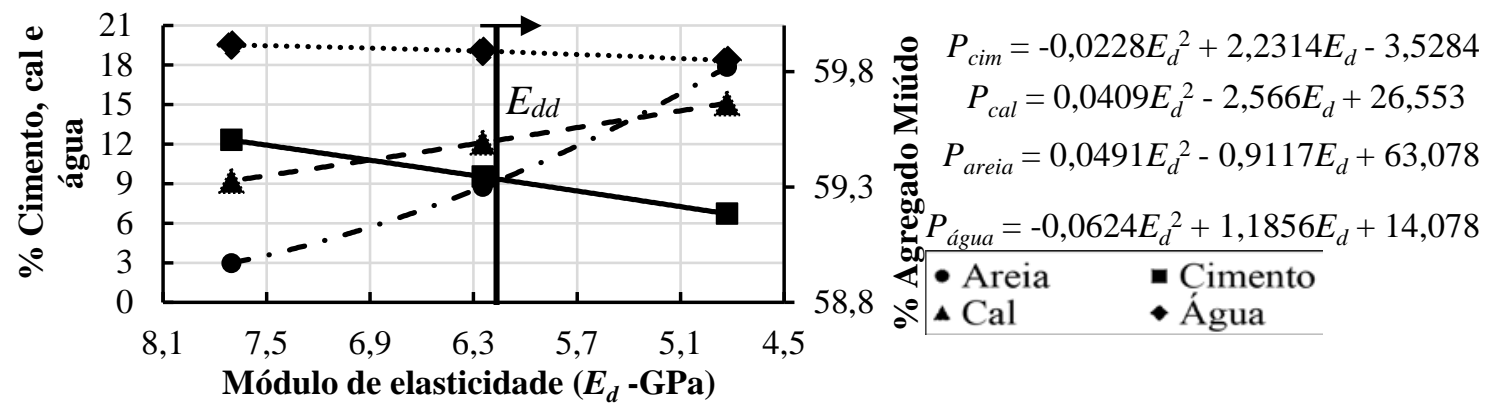

Figura 10 - Proporcionamento dos materiais versus correlação entre o módulo de elasticidade dinâmico e a resistência à tração para definição do parâmetro de dosagem $\left(E_{d} / f_{t}\right)$ para baixa fissurabilidade

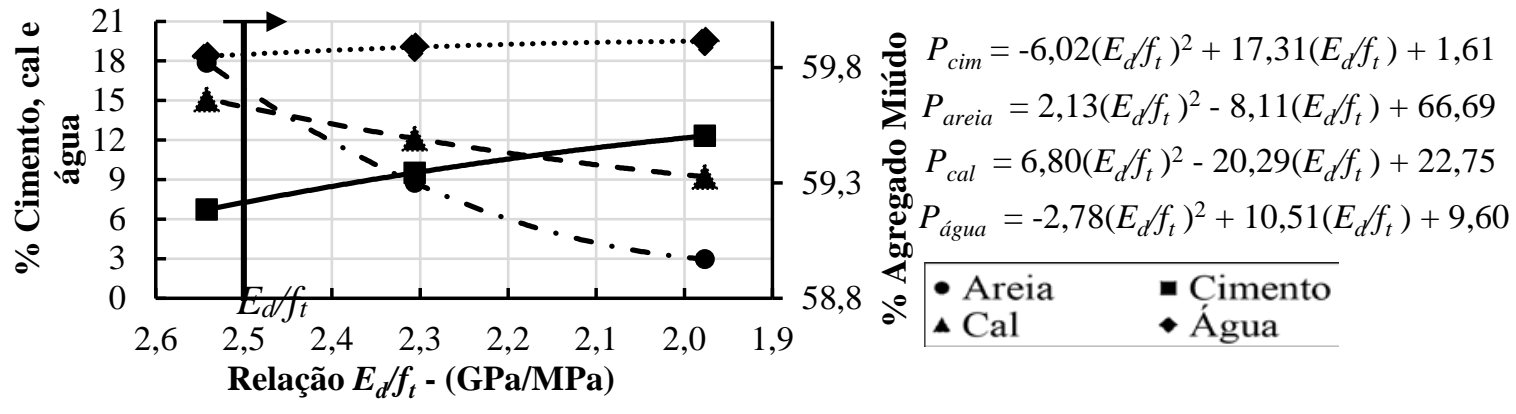

Tabela 8 - Traço ideal para areia artificial

\begin{tabular}{c|c|c|c|c}
\hline Traço final & Cimento & Cal & Areia & Água \\
\hline$\%$ & 8,53 & 13,18 & 59,47 & 18,82 \\
Volume (l) & 1,000 & 1,545 & 6,972 & 2,206 \\
Massa (kg) & 1,000 & 0,455 & 6,793 & 1,298 \\
\hline
\end{tabular}

236 Santos, W. J. dos; Alvarenga, R. de C. S. S.; Pedroti, L. G.; Silva, R. C. da; Freire, A. S.; Moraes, B. A. de; Carvalho, C. C. 
A Tabela 9 apresenta um resumo dos resultados de cada traço básico e os respectivos de desvios padrão de cada propriedade.

\section{Verificação do método}

A verificação do método consistiu na moldagem de corpos de prova (CPs) de argamassa para ensaios segundo as propriedades exigidas e comparação destes com os valores previstos. Os resultados podem ser vistos na Tabela 10. São apresentados os valores médios, desvio padrão e situação dos dados em relação ao teste $t$ (grau de significância de 0,05 ), que buscou verificar se os valores atendiam aos parâmetros estipulados (maiores ou menores que $F_{k}$, conforme o caso).

O coeficiente de capilaridade se mostrou bem inferior ao limite de dosagem, mas ainda demonstrando que há boa quantidade de poros permeáveis. Os dados também indicaram baixa fissurabilidade ( $E_{d}<7 \mathrm{GPa}$ e $E_{d} / f_{t}<2.500$ ), o que demonstra que as argamassas produzidas têm indicativo de alta durabilidade e eficiência quanto aos parâmetros analisados.

\section{Avaliação da metodologia dosagem}

Diante dos resultados e verificações experimentais, pode-se afirmar que o método é viável, com parâmetros e condições de aplicação exequíveis para os agregados artificiais de britagem. A forma de obtenção se mostrou eficiente e prática; além disso, destaca-se que os procedimentos sugeridos permitem a otimização e a avaliação das argamassas de revestimento, demonstrando como os constituintes interferem nas propriedades desses compósitos, seja no estado fresco ou endurecido. A escolha do traço ideal se mostrou adequada, convergindo para um material mais econômico (menor consumo de aglomerante), durável (dependência entre resistência, módulo de elasticidade, porosidade, absorção e as condições do local de aplicação) e sustentável (materiais mais eficientes e duráveis).

Tabela 9 - Resultados encontrados para cada traço básico acrescidos do desvio padrão (DP)

\begin{tabular}{c|c|c|c|c|c|c}
\hline Propriedade & \multicolumn{2}{|c|}{ Traço 1 } & \multicolumn{2}{c|}{ Traço 2 } & \multicolumn{2}{c}{ Traço 3 } \\
\hline & Média & DP & Média & DP & Média & DP \\
\hline$f_{c}(\mathrm{MPa})$ & 4,04 & 0,16 & 7,13 & 0,31 & 11,44 & 0,446 \\
$f_{t}(\mathrm{MPa})$ & 1,90 & 0,03 & 2.71 & 0,09 & 3,90 & 0,03 \\
$A_{d}(\mathrm{MPa})$ & 0,323 & 0,02 & 0,467 & 0,012 & 0,620 & 0,027 \\
$C C\left(\mathrm{~g} / \mathrm{dm}^{2} . \mathrm{min}^{1 / 2}\right)$ & 8,13 & 0,25 & 4,50 & 0,18 & 2,10 & 0,08 \\
$\gamma_{\text {seca }}(\mathrm{kg} / \mathrm{l})$ & 2,012 & 0,008 & 2,016 & 0,005 & 2,006 & 0,009 \\
Jfresca $_{(\mathrm{kg} / \mathrm{l})}$ & 2,027 & 0,025 & 2,096 & 0,026 & 2,122 & 0,018 \\
$E_{d}(\mathrm{Gpa})$ & 4,83 & 0,070 & 6,25 & 0,060 & 7,71 & 0,088 \\
$E_{d} / f_{t}$ & 2,54 & 0,24 & 2,31 & 0,22 & 1,98 & 0,22 \\
\hline
\end{tabular}

Tabela 10 - Valores característicos, resultados encontrados, desvio padrão e resultado do teste t

\begin{tabular}{ccccc}
\hline \multirow{2}{*}{ Propriedade } & \multicolumn{4}{c}{ Areia artificial } \\
\cline { 2 - 5 } & $\boldsymbol{F}_{\boldsymbol{k}}$ & $\boldsymbol{F}_{\text {encontrado }}$ & Desvio padrão & Teste $\boldsymbol{t}$ \\
\hline$f_{c}(\mathrm{MPa})$ & 4,00 & 5,96 & 0,44 & $*$ \\
$f_{t}(\mathrm{MPa})$ & 2,00 & 2,40 & 0,17 & $*$ \\
$A_{d}(\mathrm{MPa})$ & 0,30 & 0,40 & 0,03 & $*$ \\
$C C\left(\mathrm{~g} / \mathrm{dm}^{2} \cdot \mathrm{min}^{1 / 2}\right)$ & 7,00 & 6,07 & 0,18 & $*$ \\
$\gamma_{\text {seca }}(\mathrm{kg} / \mathrm{l})$ & 1,600 & 2,020 & 0,018 & $*$ \\
$\gamma_{\text {fresca }}(\mathrm{kg} / \mathrm{l})$ & 1,400 & 2,034 & 0,003 & $*$ \\
$E_{d}(\mathrm{Gpa})$ & 7,00 & 5,58 & 0,04 & $*$ \\
$E_{d} / f_{t}$ & 2500 & 2321 & 38 & $*$ \\
\hline
\end{tabular}

Nota: Legenda:

\footnotetext{
$*_{0}$ teste $t$ permitiu constatar que os valores encontrados em cada propriedade atendiam aos limites estipulados $(p<0,05)$;

$F_{k}$ - Valor característico; e

Fencontrado - Valor encontrado para a propriedade.
} 
Devido ao fato de ser um método experimental, há um volume de trabalho relativamente grande, contudo se constata que o processo de dosagem pode ser estruturado em planilha eletrônica, que reduz expressivamente o volume de trabalho, e para a definição das propriedades podem ser consideradas aquelas realmente necessárias às condições ambientais e de aplicação, e depois avaliar as demais somente para o traço ideal. Desde que os materiais mantenham características semelhantes, o método se mantém válido ou podem-se fazer ajustes (como identificado na fase de ajustes dos traço), conforme a alteração das características dos materiais ou alterações das condições de aplicação e exigências do local.

\section{Análise de microestrutura por microscópio digital}

As Figuras 11a e 11b apresentam as imagens por microscópio digital, e a Figura 12 apresenta área dos poros das imagens por microscópio digital das argamassas dos traços básicos e ideal através do programa de tratamento de imagens ImageJ dos três traços básicos e do traço ideal das argamassas de revestimento.

Analisando as Figuras 11a e 11b, observa-se que os valores das áreas dos poros são muito próximos para os quatro traços, demonstrando que a variação de resistência mecânica nesses traços não influenciou significativamente a morfologia da matriz cimentícia com o agregado. Percebe-se que o processo de dosagem permitiu obter traços com caraterísticas diferentes, mas com morfologia interna semelhante, o que garantirá boa durabilidade.

Para facilitar a análise dos poros, executou-se uma aproximação dos diâmetros pela obtenção de área equivalente à área dos poros através de um poro esférico (Tabela 11). Poucos poros se mostraram próximos ao perfil esférico (presença do aditivo incorporador de ar da cal), contudo se adotou como uma estimativa para buscar uma possível qualificação deles.

Pode-se verificar a presença de alguns poros mais esféricos nos traços ricos em cal, originados pelo aditivo incorporador de ar presente nesse tipo de aglomerante para garantir a plasticidade da argamassa, que tem $100 \%$ de óxido de cálcio hidratado e não requer a mistura prévia desse material a areia e a água. Constata-se que os poros que continham água acabam se unindo durante o processo de cura para permitir a evaporação, sendo que o uso da cal controla essa saída pelo efeito de retenção de água. Os poros originados pelo aditivo presente na cal estão preenchidos por ar e acabam se mantendo isolados, levando à redução das propriedades mecânicas, do módulo de elasticidade, e promovendo uma estrutura mais estanque à água e aos agentes agressivos.

Quando designados, segundo a classificação dos tamanhos da IUPAC (International Union of Pure na Applied Chemistry), há muitos poros classificados como megaporos $(>7,5 \mu \mathrm{m})$. Outro fato a se destacar é a interligação dos poros nos traços mais fracos, convergindo para maiores coeficientes de capilaridade $\left(\approx 8 \mathrm{~g} / \mathrm{dm}^{2} \mathrm{~min}^{1 / 2}\right)$, embora ainda dentro dos limites de classificação da NBR 13281 (ABNT, 2005a). Isso não foi tão visível nos traços mais ricos em cimento, haja vista a existência de poros também grandes, porém não interligados, gerando menos capilares para a passagem da água. Logo, o uso da cal também na areia artificial se mostra importante para garantir maior durabilidade às argamassas.

$\mathrm{O}$ traço ideal se apresentou muito semelhante às condições encontradas para o traço básico 2 e pode ser definido com predominância de megaporos. Esses poros convergem para coeficientes de capilaridade $\left(\approx 4 \mathrm{~g} / \mathrm{dm}^{2} \mathrm{~min}^{1 / 2}\right)$ dentro dos limites da NBR 13281 (ABNT, 2005a), conforme estabelecido no processo de dosagem.

\section{Conclusões}

Os resultados e imagens permitiram a confirmação e interação dos conceitos e conhecimentos abordados, comprovando a exequibilidade dos procedimentos e técnicas propostos e, acima de tudo, permitindo a ampliação do conhecimento acerca das argamassas de revestimento, principalmente no que tange ao processo de dosagem, à influência dos constituintes neste compósito cimentício e às correlações e interdependências entre as propriedades analisadas.

Diante dos resultados e verificações experimentais do trabalho, percebe-se que o método de dosagem proposto permite a estruturação de um proporcionamento de materiais de forma eficiente, gerando argamassas de boa qualidade (conforme requisitos) e que atendem aos parâmetros técnicocientíficos e normativos e às condições do local de uso e de aplicação especificados durante o processo de dosagem. 
Figura 11 - (a) Imagens de microscópio digital e (b) imagens tratadas para evidenciar os poros das argamassas dos traços básicos e ideal

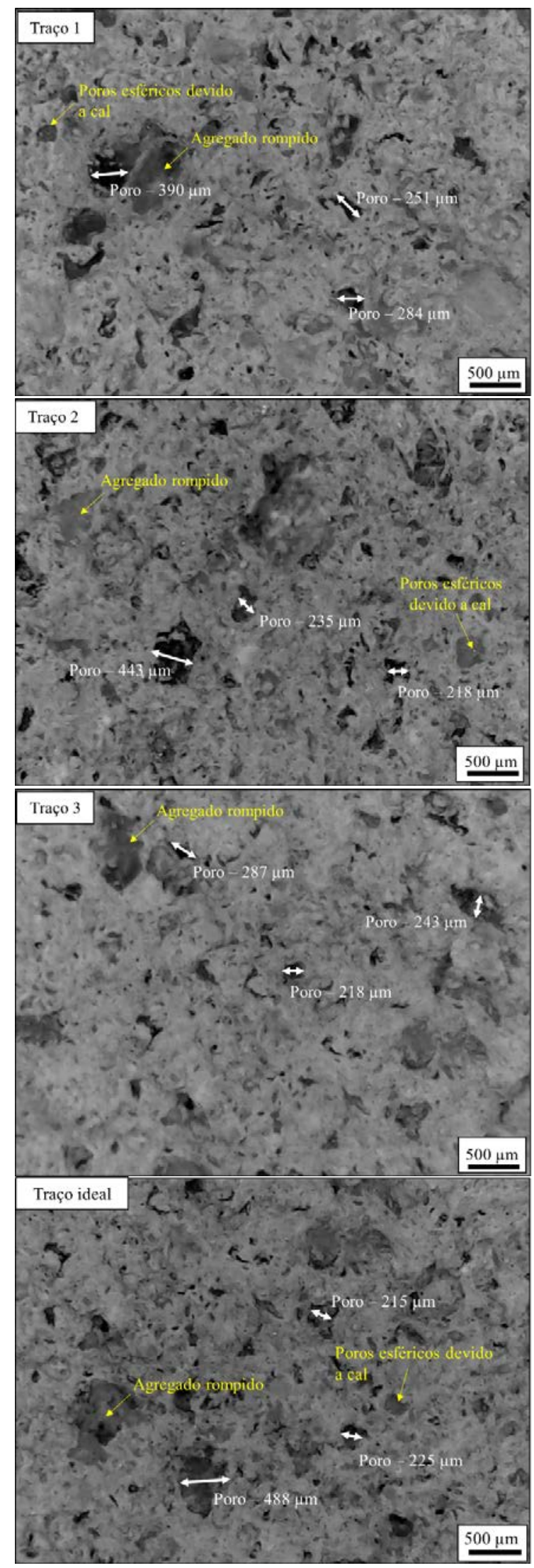

(a)

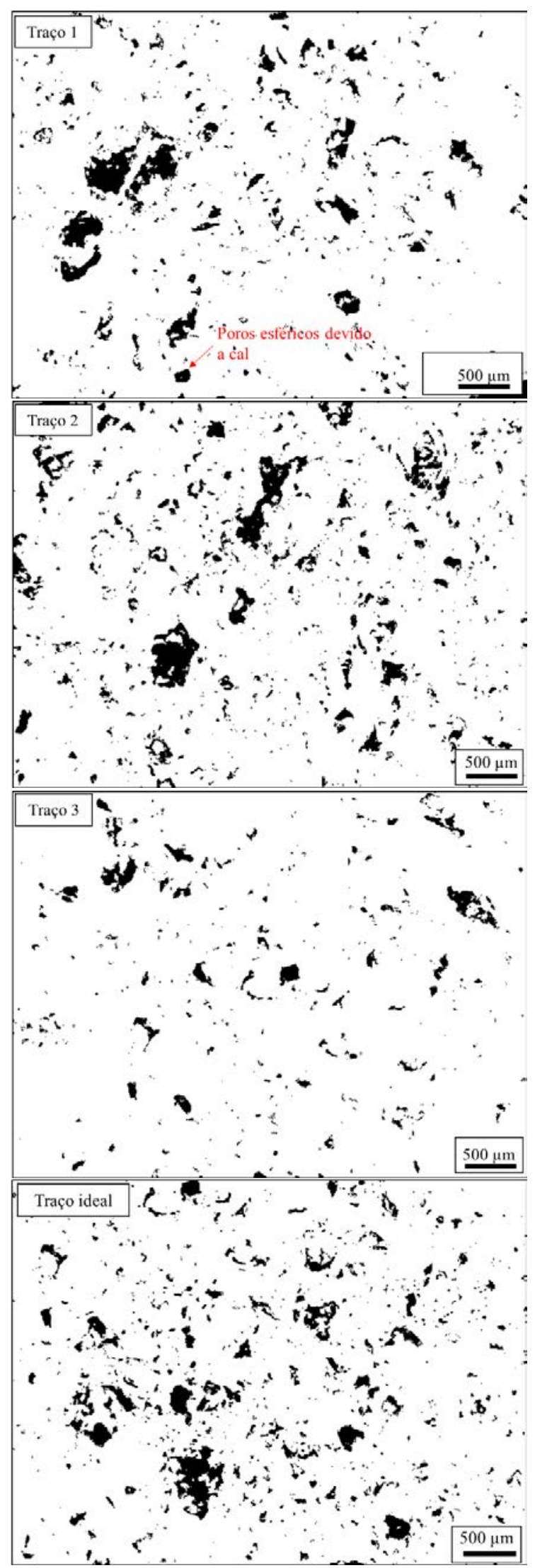

(b) 
Tabela 11 - Estimava do diâmetro equivalente esférico dos poros

\begin{tabular}{c|c|c|c|c}
\hline Traço & $\begin{array}{c}\text { Área } \\
\mathbf{D 5 0}\left(\mathbf{m m}^{2}\right)\end{array}$ & $\begin{array}{c}\text { Diâmetro esférico } \\
\mathbf{D 5 0}(\boldsymbol{\mu m})\end{array}$ & $\begin{array}{c}\text { Área } \\
\mathbf{D 9 0}\left(\mathbf{m m}^{2}\right)\end{array}$ & $\begin{array}{c}\text { Diâmetro esférico } \\
\mathbf{D 9 0}(\boldsymbol{\mu m})\end{array}$ \\
\hline 1 & 0,0025 & 56,41 & 0,0250 & 178,41 \\
2 & 0,0017 & 46,52 & 0,0210 & 163,51 \\
3 & 0,0026 & 57,53 & 0,0220 & 167,37 \\
Ideal & 0,0018 & 47,87 & 0,0240 & 164,81 \\
\hline
\end{tabular}

Figura 12 - Área dos poros das imagens por microscópio digital das argamassas dos traços básicos e ideal através do programa de tratamento de imagens ImageJ

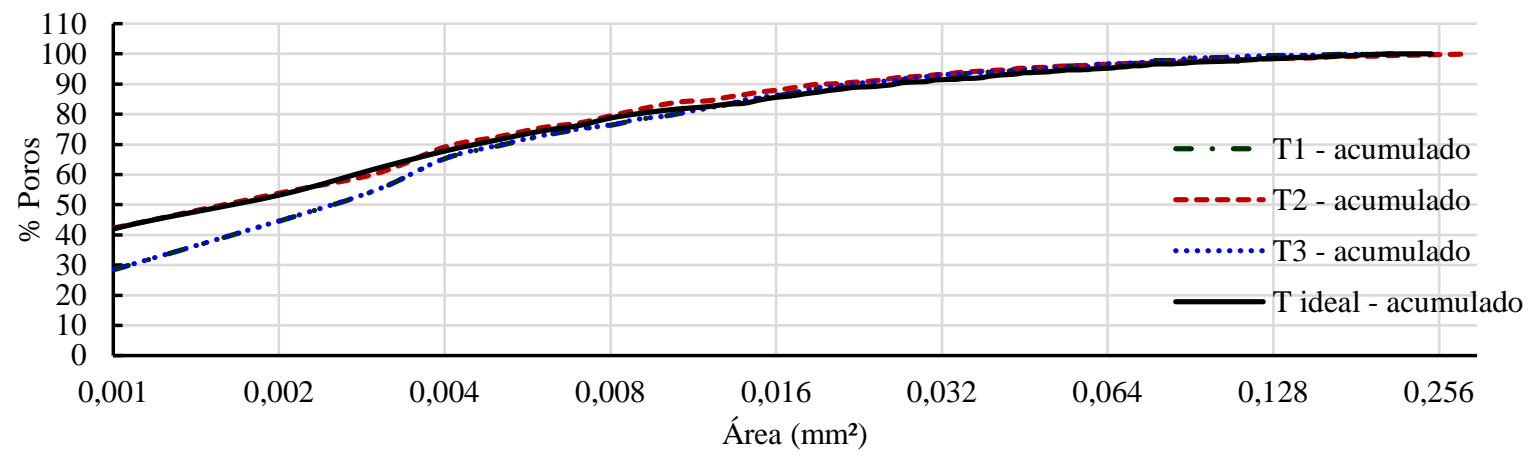

Destaca-se que este trabalho se baseou nos parâmetros da NBR 13281 (ABNT, 2005a) para definir os requisitos, contudo o método de dosagem proposto permite que o tecnologista defina as propriedades e os parâmetros que julgar convenientes para as necessidades da edificação, de modo a atender aos parâmetros de qualidade e durabilidade para o sistema de revestimento. Quanto aos materiais, foram realizados testes com outros tipos de areia e cimento (não apresentados neste trabalho) e para condições diferentes, como o caso de alvenaria estrutural, e percebe-se o bom desempenho do método para a obtenção de argamassas mistas.

Conclui-se que a metodologia proposta é eficiente e permite obter argamassas de revestimento de boa qualidade e de acordo com as condições do ambiente e da forma de aplicação, com agregado miúdo artificial de britagem. O processo apresentou uma série de procedimentos de operação relativamente simples, comuns aos utilizados na construção civil para obter o traço ideal. Acreditase que o uso de planilhas eletrônicas e definição das propriedades mais relevantes, conforme o item 2.6, para os traços básicos e a verificação das demais propriedades somente para o traço ideal podem ser uma boa forma de reduzir os trabalhos com o processo experimental.

\section{Referências}

ALLWOOD, J.; ASHBY, M. G. T. W. E. Material Efficiency: a white paper. Resources, Journal Conservation and Recycling, v. 55, p. 362-81. 2011.

AMERICAN SOCIETY FOR TESTING AND

MATERIALS. ASTM C270-14a: standard specification for mortar for unit masonry. West Conshohocken, 2014.

\section{ASSOCIAÇÃO BRASILEIRA DE NORMAS}

TÉCNICAS. NBR 15630: argamassa para assentamento e revestimento de paredes e tetos: determinação do módulo de elasticidade dinâmico através da propagação de onda ultrassônica. Rio de Janeiro, 2009b.

\section{ASSOCIAÇÃO BRASILEIRA DE NORMAS}

TÉCNICAS. NBR 13276: argamassa para assentamento e revestimento de paredes e tetos: determinação do índice de consistência. Rio de Janeiro, 2016.

\section{ASSOCIAÇÃO BRASILEIRA DE NORMAS}

TÉCNICAS. NBR 13278: argamassa para assentamento e revestimento de paredes e tetos: determinação da densidade de massa e do teor de ar incorporado. Rio de Janeiro, 2005b.

\section{ASSOCIAÇÃO BRASILEIRA DE NORMAS}

TÉCNICAS. NBR 13279: argamassa para assentamento e revestimento de paredes e tetos: determinação da resistência à tração na flexão e à compressão. Rio de Janeiro, 2005c. 
ASSOCIAÇÃO BRASILEIRA DE NORMAS TÉCNICAS. NBR 13280: argamassa para assentamento e revestimento de paredes e tetos: determinação da densidade de massa aparente no estado endurecido. Rio de Janeiro, 2005d.

ASSOCIAÇÃO BRASILEIRA DE NORMAS TÉCNICAS. NBR 13281: argamassa para assentamento e revestimento de paredes e tetos: requisitos. Rio de Janeiro, 2005a.

\section{ASSOCIAÇÃO BRASILEIRA DE NORMAS} TÉCNICAS. NBR 13528: revestimento de paredes e tetos de argamassas inorgânicas: determinação da resistência de aderência à tração. Rio de Janeiro, 2010b.

\section{ASSOCIAÇÃO BRASILEIRA DE NORMAS}

TÉCNICAS. NBR 15259: argamassa para assentamento e revestimento de paredes e tetos: determinação da absorção de água por capilaridade e do coeficiente de capilaridade. Rio de Janeiro, 2005e.

\section{ASSOCIAÇÃO BRASILEIRA DE NORMAS}

TÉCNICAS. NBR 7218: agregados: determinação do teor de argila em torrões e materiais friáveis. Rio de Janeiro, 2010.

\section{ASSOCIAÇÃO BRASILEIRA DE NORMAS} TÉCNICAS. NBR 7218: agregados: determinação do teor de argila em torrões e materiais friáveis. Rio de Janeiro, 2010.

ASSOCIAÇÃO BRASILEIRA DE NORMAS TÉCNICAS. NBR NM 30: agregados miúdos: determinação da absorção de água. Rio de Janeiro, 2000.

\section{ASSOCIAÇÃO BRASILEIRA DE NORMAS}

TÉCNICAS. NBR NM 45: agregados: determinação da massa unitária e do volume de vazios. Rio de Janeiro, 2006.

\section{ASSOCIAÇÃO BRASILEIRA DE NORMAS} TÉCNICAS. NBR NM 46: agregados: determinação do material fino que passa através da peneira $75 \mu \mathrm{m}$, por lavagem. Rio de Janeiro, 2001a.

ASSOCIAÇÃO BRASILEIRA DE NORMAS TÉCNICAS. NBR NM 49: agregado miúdo: determinação de impurezas orgnicas. Rio de Janeiro, 2001b.

\section{ASSOCIAÇÃO BRASILEIRA DE NORMAS}

TÉCNICAS. NBR NM 52: determinação da massa específica de agregados miúdos por meio de frasco Chapman. Rio de Janeiro, 2009a.
BAHIENSE, A. V. et al. Utilização do Planejamento Experimental na Incorporação do Resíduo da Indústria Cerâmica em Argamassas Para Obtenção da Capacidade de Retenção de Água. Revista Cerâmica, v. 54, p. 395-403, 2008.

BARBOSA, M. T. G.; SANTOS, W. J. ARGAD: high performance mortar. Portugal SB13: Contribution of Sustetainable Building to Meet. 2013.

CARASEK, H. C. Argamassas. In: ISAIA, G. C. Materiais de Construção Civil e Princípios de Ciência e Engenharia de Materiais. 2. ed. São Paulo: Ibracon, 2010.

CARDOSO, F. A. Método de Formulação de Argamassas de Revestimento Baseado em Distribuição Granulométrica e Comportamento Reológico. São Paulo, 2009. Tese (Doutorado em Engenharia Civil) - Escola Politécnica, Universidade de São Paulo, São Paulo, 2009.

CARNEIRO, A. M. P. Dosagem de Argamassa Através de Curvas Granulométricas. São Paulo, 1999. Boletim Técnico da Escola Politécnica da USP, BT/PCC/237.

DESTEFANI, A. Z.; HOLANDA, J. N. F. Utilização do Planejamento Experimental em Rede Simplex no Estudo de Resíduo de Rocha Ornamental Como Filler Para Obtenção de Máxima Compacidade. Revista Cerâmica, v. 57, p. 491-498, 2011.

FARIA, P.; SANTOS, T.; AUBERT, J. Experimental Characterization of an Earth EcoEfficient Plastering Mortar. Journal of Materials in Civil Engineering, v. 28, n. 1, 2015.

FREITAS, C. de. Argamassas de Revestimento Com Agregados Miúdos de Britagem da Região Metropolitana de Curitiba: propriedades no estado fresco e endurecido. Curitiba, 2010. Dissertação (Mestrado em Construção Civil) Escola de Engenharia, Universidade Federal do Paraná, Curitiba, 2010.

GOMES, A. O.; NEVES, C. M. M. Proposta de Método de Dosagem Racional de Argamassas Contendo Argilominerais. Ambiente Construído, Porto Alegre, v. 2, n. 2, p. 19-30, abr./jun. 2002.

HADDAD, L. D. O. Estudo da Influência da Forma e Granulometria dos Agregados nas Propriedades das Argamassas de Revestimento. 113 f. Belo Horizonte, 2015. Dissertação (Mestrado em Engenharia Civil) - Programa de Pós-Graduação em Construção Civil, Universidade Federal de Minas Gerais, Belo Horizonte, 2015. 
HWANG, E. H.; SOO KO, Y. Comparison of Mechanical and Physical Properties of SBRPolymer Modified Mortars Using Recycled Waste Materials. Journal of Industrial and Engineering Chemistry, v. 14, p. 644-650, Set. 2008.

KADRI, H.; DUVAL, R. R. Effect of Ultrafine Particles on Heat of Hydration of Cement Mortars. ACI Materials Journal, p. 138-142, Mar./Apr. 2002.

LARA, D. et al. Dosagem Das argamassas. In: SIMPÓSIO BRASILEIRO DE TECNOLOGIA DAS ARGAMASSAS, 1., Goiânia, 1995. Anais... Goiânia: ANTAC, 1995.

MEHTA, P. K.; MONTEIRO, P. J. M. Concreto: microestrutura, propriedades e materiais. 3. ed. São Paulo: Pini, 2014.

MENG, L. et al. Shape and Size Effects on the Packing Density of Binary Spherocylinders. Powder Technology, v. 228, p. 284-294, 2012.

PAN, H.; WENG, G. Investigation of the AgeDependent Constitutive Relations of Mortar. Journal of Engineering Mechanics, v. 138, n. 3, p. 297-306, 2012.

PENG, Y.; HU, S.; DING, Q. Dense Packing Properties of Mineral Admixtures in Cementitious Material. Particuology Science and Technology of Particles, v. 7, p. 399-402, 2009.

SAHMARAN, M. et al. Influence of Aggregates Type and Sinze on Ductility and Mechanical Properties of Engineered Cementitious Composites. ACI Materials Journal, p. 308-316, May/Jun. 2009.
SANTOS, W. J. Argamassa de Alto

Desempenho. Juiz de Fora, 2011. 209 f.

Dissertação (Mestrado em Engenharia Civil) Escola de Engenharaia, Universidade Federal de Juiz de Fora, Juiz de Fora, 2011.

SANTOS, W. J. Desenvolvimento de Metodologia de Dosagem de Argamassas de Revestimento e Assentamento. 179 f. Viçosa, 2014. Dissertação (Mestrado em Engenharia Civil) - Pós-graduação em Engenharia Civil, Universidade de Viçosa, Viçosa, 2014.

SELMO, S. M. S. Dosagem de Argamassa de Cimento Portland e Cal Para Revestimento Externo de Fachadas dos Edifícios. São Paulo, 1989. 227 f. Dissertação (Mestrado) - Escola Politécnica, Universidade de São Paulo, São Paulo, 1989.

SELMO, S. M. S.; HELENE, P. R. L. Dosagem de Argamassa de Cimento Portland e Cal Para Revestimento Externo de Fachadas dos Edifícios. São Paulo, 1991. Boletim Técnico Escola Politécnica da Universidade de São Paulo.

SILVA, N. G. Argamassa de Revestimento de Cimento, Cal e Areia Britada de Rocha Calcária. Curitiba, 2006. 164 f. Dissertação (Mestrado em Engenharia Civil) - Escola de Engenharia, Universidade Federal do Paraná, Curitiba, 2006.

\section{Agradecimentos}

Agradecer ao apoio das instituições: UFV e UFMG; e aos órgãos de fomento: CAPPES, FAPEMIG, CNPQ. 


\section{White J osé dos Santos}

Departamento de Engenharia de Materiais e Construção Civil, Escola de Engenharia | Universidade Federal de Minas Gerais | Av. Antônio Carlos, 6627, Sala 3320, Bloco 1, Prédio da Engenharia, Pampulha | Belo Horizonte - MG - Brasil | CEP 31270-901| Tel.: (31) 3249-1809 | E-mail: white.santos@demc.ufmg.br

\section{Rita de Cassia Silva Sant'Ana Alvarenga}

Programa de Pós-Graduação em Engenharia Civil | Universidade Federal de Viçosa | Av. Ph Rolfs, s/n | Viçosa - MG - Brasil | CEP 36570 900 | Tel.: (31) 3899-1488 | E-mail: ritadecassia@ufv.br

\section{Leonardo Gonçalves Pedroti}

Programa de Pós-Graduação em Engenharia Civil | Universidade Federal de Viçosa | E-mail: leonardo.pedroti@ufv.br

Reginaldo Carneiro da Silva

Departamento de Engenharia Civil | Universidade Federal de Viçosa | Tel.: (31) 3899-1486 | E-mail: recsilva@ufv.br

\section{Antonio Serpa Freire}

Graduando em Egenharia Civil | Universidade Federal de Minas Gerais | E-mail: antonio.asfreire@yahoo.com.br

Bruna Antunes de Moraes

Graduando em Egenharia Civil Universidade Federal de Minas Gerais | E-mail: antunesbruna@hotmail.com

\section{Clara Cordeiro Carvalho}

Graduando em Egenharia Civil Universidade Federal de Minas Gerais | E-mail: claraccarvalho@hotmail.com

\section{Revista Ambiente Construído}

Associação Nacional de Tecnologia do Ambiente Construído

Av. Osvaldo Aranha, 99 - 3o andar, Centro

Porto Alegre - RS - Brasil

CEP 90035-190

Telefone: +55 (51) 3308-4084

Fax: +55 (51) 3308-4054

www. seer. ufrgs. br/ ambienteconstruido

E-mail: ambienteconstruido@ufrgs.br 